\title{
Perancangan Sistem Pengajuan Cuti Izin Sakit (CIS) Menggunakan Platform Pega System
}

\author{
Kevin Alexander Harjanto', Magdalena Ariance Ineke Pakereng ${ }^{2}$ \\ 1,2 Fakultas Teknologi Informasi, Universitas Kristen Satya Wacana \\ e-mail: ${ }^{1}$ kevin.alexander208@gmail.com, ${ }^{2}$ ineke.pakereng@uksw.edu
}

\begin{abstract}
Abstrak - PT Asuransi Sinar Mas merupakan perusahaan yang bergerak pada bilang layanan asuransi dan PT Asuransi Sinar Mas memiliki karyawan sekitar 2873 dan akan terus bertambah. Dengan banyaknya karyawan di dalam PT Asuransi Sinar Mas maka dibuatlah aplikasi pengajuan CIS yang bertujuan untuk lebih memudahkan dalam melakukan pengajuan izin / cuti kerja. Cuti / izin sakit dapat digunakan atau diajukan ketika karyawan tidak dapat bekerja karena memiliki berbagai halangan yang memungkinkan untuk tidak bekerja. Aplikasi ini dibuat menggunakan Pega System 8 yang berfokus pada pengelolaan Business Process Management (BPM) sebagai perantara antara komunitas bisnis dan metode yang digunakan dalam pembuatan aplikasi ini adalah Agile. Setelah dibuatnya aplikasi ini dan melakukan pengujian, aplikasi ini menghasilkan pengaruh terhadap sistem pengajuan yang menjadi lebih efisien karena tidak memakan waktu yang lama. Dengan adanya sistem ini, karyawan dapat melakukan pengajuan kapan saja dan dimana saja tanpa harus dilakukan secara manual atau tatap muka secara langsung.
\end{abstract}

Kata Kunci : Pengajuan CIS, Pega System 8, Karyawan

Abstract - PT Asuransi Sinar Mas is a company engaged in insurance service and has around three thousand employees which will countinue to grow. Due to large amount of employees, CIS application was made to ease filing sick permit process. Sick leave can be submitted when employee needs to take leave of absence due to having urgent conditions. This application was made using Pega System 8 which focus on Business Process Management (BPM) as an intermediary between the business community and the method used in the development process is Agile. After this application being developed and getting tested, resulting in more efficient filing process. By having this system, employees are able to file sick permit anytime anywhere without having to fill paperwork or meeting directly.

Keywords : Submission CIS, Pega System 8, Employee

\section{Pendahuluan}

PT Asuransi Sinar Mas adalah salah satu perusahaan asuransi terbesar di Indonesia. PT Asuransi Sinar Mas sendiri memiliki sekitar 2873 karyawan pada tahun 2019 ini. Visi dari PT Asuransi Sinar Mas adalah Menjadi perusahaan asuransi profesional dan terpercaya dengan memberikan nilai yang berarti kepada nasabah, perusahaan reasuransi, agen, rekanan, pemegang saham dan karyawan kami. Sumber daya manusia merupakan aset yang paling penting dalam PT Asuransi Sinar Mas.

Demi terjaganya aset Sumber daya manusia maka PT Asuransi Sinar Mas harus memberikan fasilitas yang baik. Dengan meningkatkan kinerja perusahaan agar mampu bersaing dan bertahan dalam persaingan bisnis (Ratnawati and Subudi 2018). Dengan cara tersebut maka PT Asuransi Sinar Mas dapat menempati posisi-posisi strategis.

Perusahaan yang baik adalah perusahaan yang selalu memperhatikan permasalahan yang terjadi didalam perusahaannya (Satria Rachmadinata and Gita Ayuningtias 2014), sehingga dapat terjaga performa pegawainya. Salah satu usaha yang dilakukan perusahaan adalah membuat sistem Pengajuan Cuti Izin Sakit (CIS). CIS dapat digunakan oleh pegawai untuk kepentingan tidak masuk kerja dengan alasan tertentu. Jenis cuti yang 
digunakan di PT Asuransi Sinar Mas adalah Cuti Haid (CH), Cuti Khusus (CK), Cuti Nikah (CN), Cuti Tahunan (CT), Cuti Tahun Lalu (CTL), Izin Per Hari (IH), Izin Per Jam (IJ), Memo Per Hari $(\mathrm{MMH})$, Memo Per Jam (MMJ), Surat Dengan Surat Dokter (SDS), Surat Tanpa Surat Dokter (STS).

Sistem CIS di PT Asuransi Sinar Mas masih menggunakan sistem yang lama, oleh karena itu penulis memperbarui sistem ini untuk mempermudah dalam manajemen agar lebih efisien dan efektif. Sistem ini dibuat menggunakan platform pega system yang merupakan platform yang tergolong masih baru. Pega System merupakan platform yang berorientasi proses bisnis atau Business Process Management (BPM) dengan menggunakan bahasa pemrograman java (Darungo and Tanaamah 2018). BPM bertujuan untuk meningkatkan kinerja perusahaan dengan mengelola proses bisnis perusahaan (Chaudhari, Nagpal, and H. 2017).

Pengimplementasian sistem baru menggunakan Pega Systems dapat membantu menjawab permasalahan untuk memberikan layanan yang lebih baik dalam mengurangi redundansi data yang ada (Kalluri 2015). Pega System menggunakan fitur-fitur yang mempermudah bagi pengguna sehingga lebih efisien. Pengguna juga dimudahkan dengan tidak melakukan full coding.

\section{Metode Penelitian}

Metode penelitian yang digunakan dalam penelitian ini adalah metode Agile, yaitu metode pengembangan perangkat lunak yang berbasis pada Iterative dan Incremental Model. Metode penelitian ini mengembangkan perangkat lunak yang memiliki requirement yang mudah berubah dan cepat, ini dikarenakan adanya pengembangan secara parsial dan kelompok-kelompok kerja dalam menyelesaikan modul yang disusun berdasarkan skala prioritas. (Listiyoko, Fahrudin, and Maksum 2017)

Tahapan pengembangan sistem dengan metode agile dapat diilustrasikan dalam gambar 1 sebagai berikut

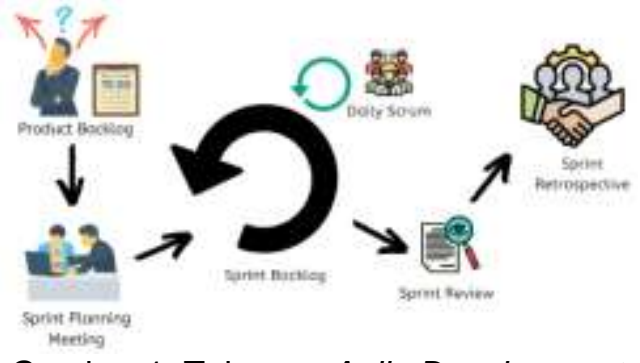

Gambar 1. Tahapan Agile Development System

- Product Backlog

Pemilik Proyek menyusun dan mengumpulkan semua requirement yang dibutuhkan dalam pembuatan sistem.

- Sprint Planning Meeting

Pemilik Proyek melakukan meeting dengan scrum master untuk menentukan estimasi waktu dan breakdown kebutuhan. Scrum master adalah membantu team dalam membangun sebuah sistem atau sebagai jembatan antara Pemilik Proyek dengan team scrum

- Sprint Backlog

Team scrum mulai melakukan pembuatan sistem dan melakukan testing secara berulang serta melakukan meeting setiap hari untuk membahas progress.

- Sprint Review

Team scrum melakukan uji coba dan melihatkan fitur-fitur yang sudah dibuat kepada pemilik proyek. Jika belum terpenuhi maka dapat mengulang tahapan scum lagi dari awal.

- Sprint Retrospective

Setelah sistem selesai dibuat berharap dapat meningkatkan kinerja team menjadi lebih baik lagi.

\section{Use Case Diagram}

Use case adalah urutan langkahlangkah yang secara tindakan saling terkait (skenario), baik terotomatisasi maupun secara manual, untuk tujuan melengkapi satu tugas bisnis tunggal (Setiyanto, Samopa, and Alwi 2013). Jika dilihat dari sudut pandang orang di luar sistem yang sedang di bangun (aktor). Diagram ini berfungsi menjelaskan secara singkat kebutuhan apa saja yang dibutuhkan dalam pembuatan sistem dan melibatkan siapa saja aktor yang menggunakan aplikasi ini. 
Use Case Diagram dapat dilihat dari Gambar 2.

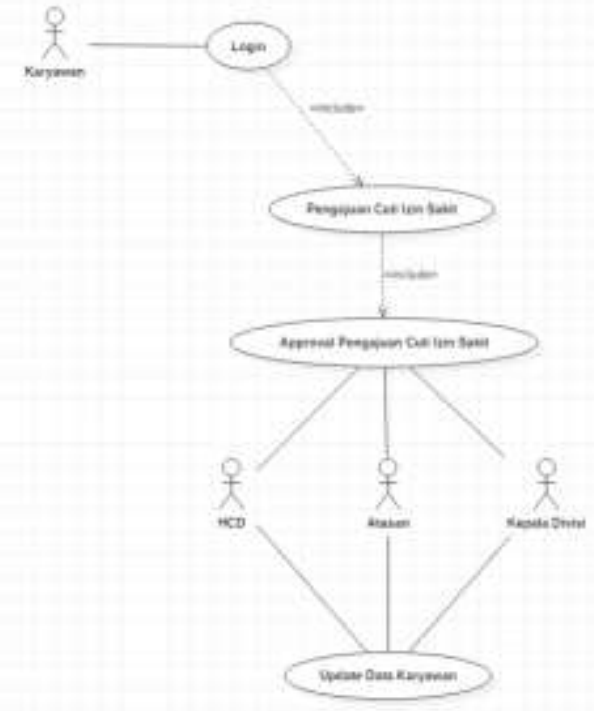

Gambar 2. Use Case Diagram

\section{Activity Diagram}

Activity Diagram merupakan diagram yang menjelaskan workflow (aliran kerja) atau aktivitas didalam sistem atau proses bisnis. Alur kerja dari sistem ini dimulai dari Karyawan telah Login, setelah melakukan Login maka akan muncul tampilan form Pengajuan Cuti Izin Sakit (CIS). Karyawan diberikan beberapa pilihan yang berisikan macam jenis cuti yang telah disediakan. Jika karyawan memilih jenis Cuti Unpaid (CU) maka setelah pengajuan akan di-approve atau reject oleh Kepala Divisi dan setelah diapprove maka akan ada pengecekan posisi bagian apakah yang melakukan approve memiliki jabatan sebagai kepala divisi atau bukan, jika bukan maka akan dikembalikan ke pilihan menu approval. Jika karyawan memilih jenis Cuti Tahun Lalu (CTL) maka setelah pengajuan akan di-approve atau reject oleh bagian HCD. Dan jika karyawan memilih jenis cuti selain CTL dan CU maka setelah pengajuan akan di-approve atau reject oleh Atasan masing-masing karyawan. Jika pengajuan sudah di-approve maka akan melakukan Update Data Karyawan sehingga pengajuan cuti sudah terbilang berhasil. Activity Diagram dapat dilihat dari Gambar 3.

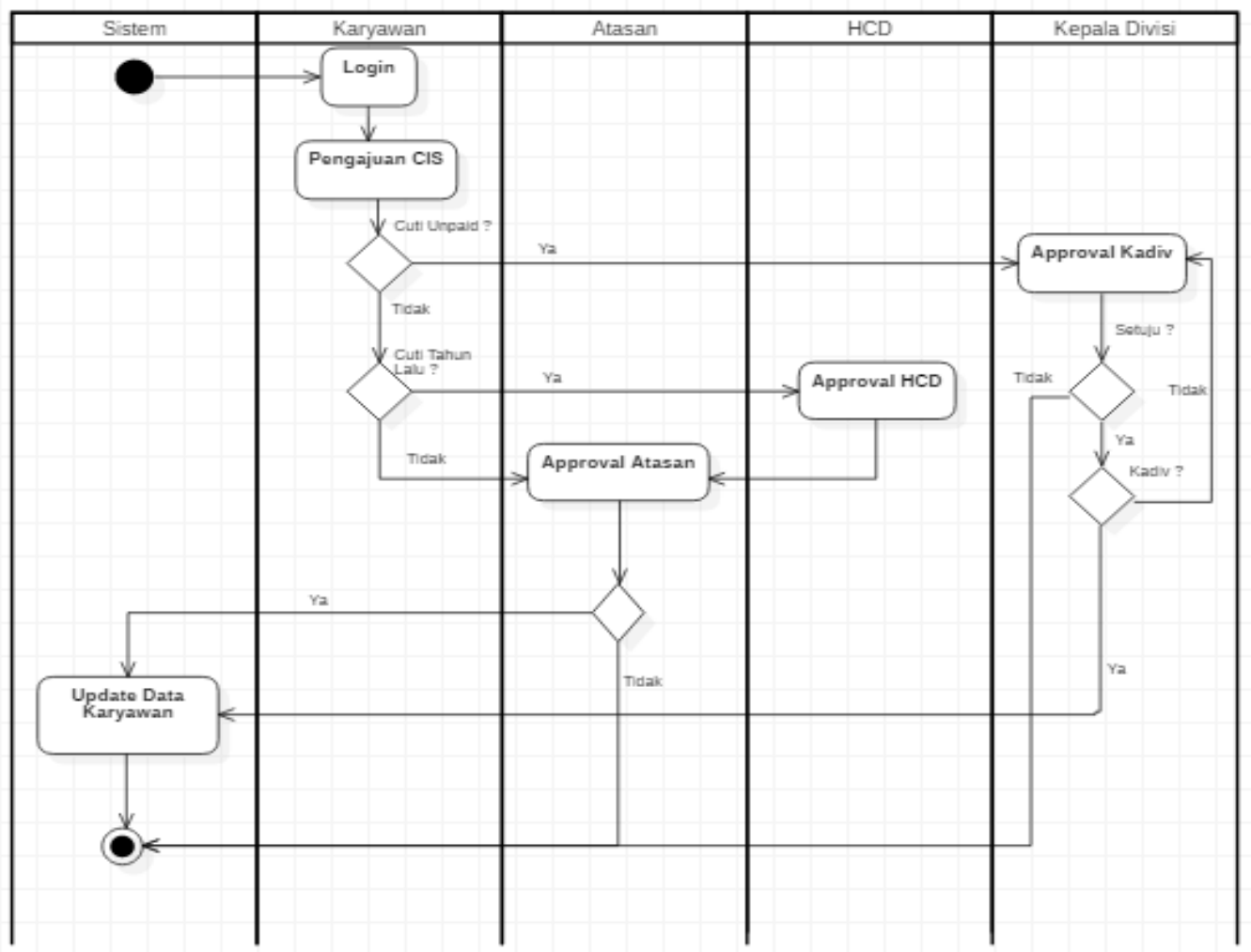

Gambar 3. Activity Diagram 


\section{Hasil dan Pembahasan}

Dalam melakukan implementasi dari Perancangan Sistem Pengajuan Cuti Izin Sakit (CIS) ini penulis menggunakan pega system. Dalam pega system menggunakan proses bisnis (BPM) untuk menentukan alur jalannya sebuah sistem tersebut. Alur proses bisnis yang sudah ditentukan kemudian diimplementasikan ke dalam Pega yaitu dengan melakukan stage dan step pada Pega (Revian Palpialy 2018). Dalam gambar 4, stage merupakan "Permohonan Cuti Izin", "Approval Atasan", "Approval Rejection" dan step merupakan
"Pengajuan Cuti Izin Sakit", "Approval Atasan", "Approval Rejection". Stage dapat disebut juga sebagai flow diagram merupakan tahapan dalam melakukan eksekusi dan step merupakan langkah dalam melakukan eksekusi dalam masingmasing stage. Dalam pega, stage juga berfungsi sebagai proses-proses kecil. Disebut proses-proses kecil karena tidak harus menjalankan proses dari awal sistem berjalan dan dapat menjalankan stage itu saja. Stage dan step dimulai atau dieksekusi dari yang paling awal ke akhir. Lebih jelasnya dapat dilihat pada Gambar 4.

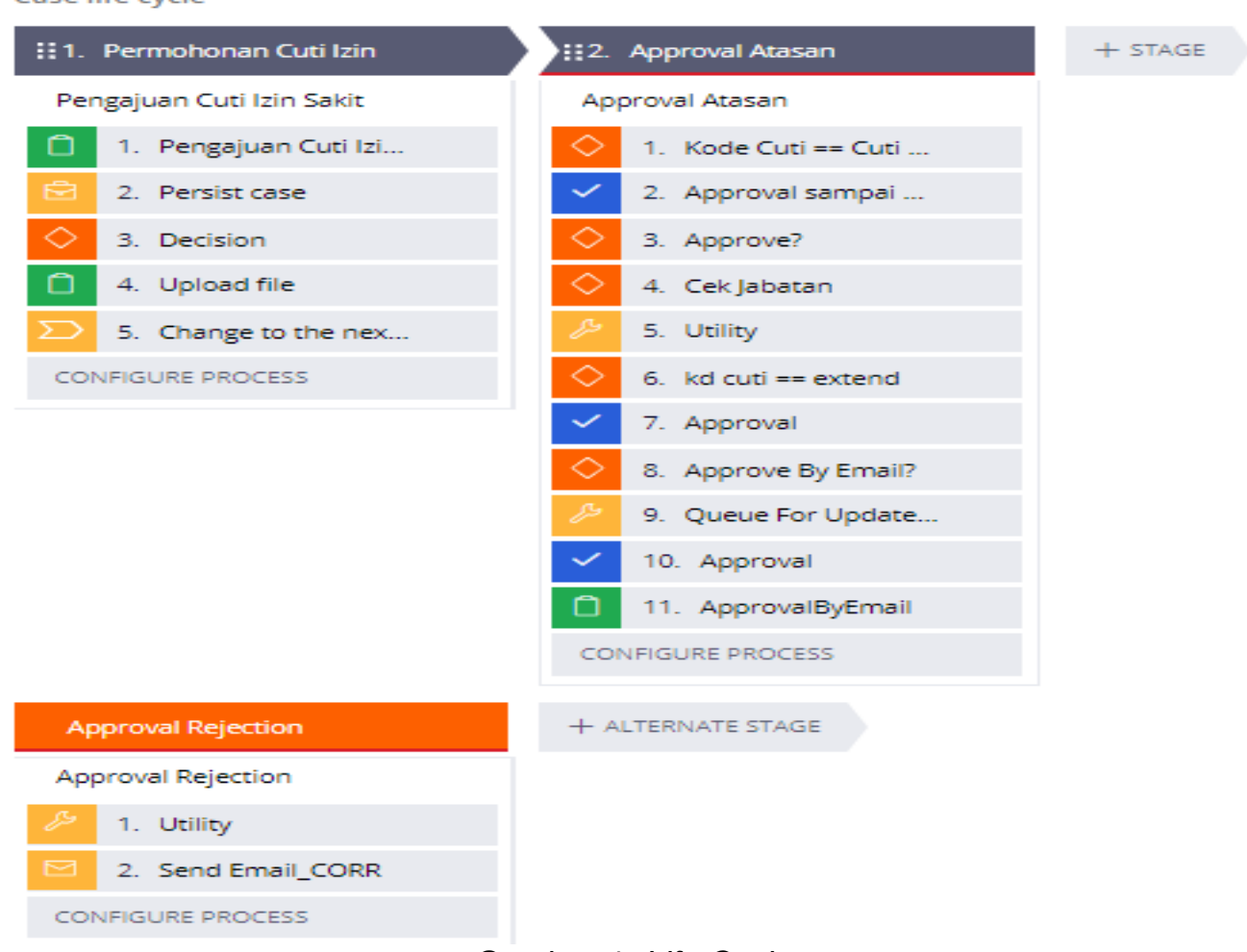

Gambar 4. Life Cycle

Flow Diagram adalah gambaran yang menjelaskan jalannya suatu sistem secara berstruktur dan secara singkat. Penjelasan flow diagram dapat dilihat pada Gambar 8.

Flow LeavePermission merupakan flow diagram yang pertama kali diproses atau dilalui. Dalam flow ini Karyawan melakukan input yang berisi pengajuan cuti izin sakit (CIS). Setelah assignment yang bertuliskan "Pengajuan Cuti Izin Sakit" terdapat connector yang berfungsi menghubungkan, yang didalamnya terdapat flow action "Detail Permohonan". Flow action tersebut terdapat section dan activity. Setelah itu akan ada pengecekan jenis cuti yang di-input, jika membutuhkan untuk upload file maka akan muncul section untuk melakukan upload file. Jika sudah maka akan menuju ke stage selanjutnya. 


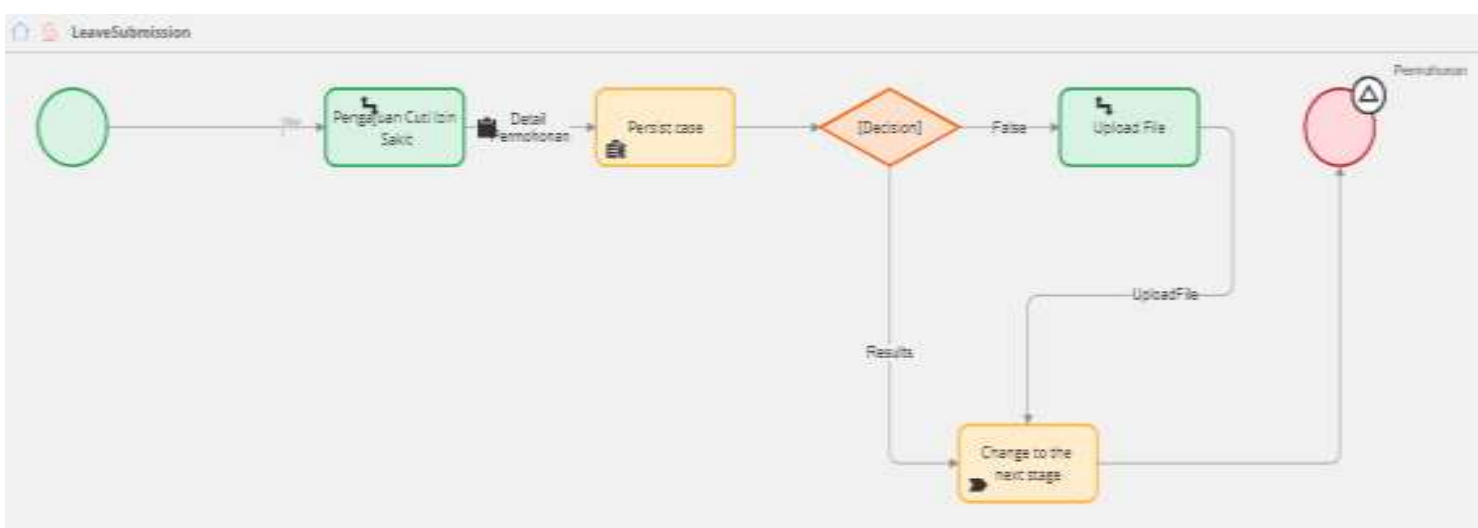

Gambar 5. Flow LeaveSubmission

Flow "ApprovalAtasan" merupakan flow yang berisikan akseptasi atasan dan update data karyawan. Setelah input cuti, kemudian lanjut dengan proses approve atau reject oleh masing-asing bagian berdasarkan jenis cutinya. Jika pengajuan sudah di-approve maka akan dilakukan update pada data karyawan dan berlanjut proses pengiriman email yang berisi keterangan pengajuan telah disetujui Jika direject, maka akan masuk dalam flow "ApprovalReject" dan melakukan pengiriman email yang berisikan keterangan permintaan dengan status telah reject. Flow approve dan reject dapat dilihat pada Gambar 6 dan Gambar 7.

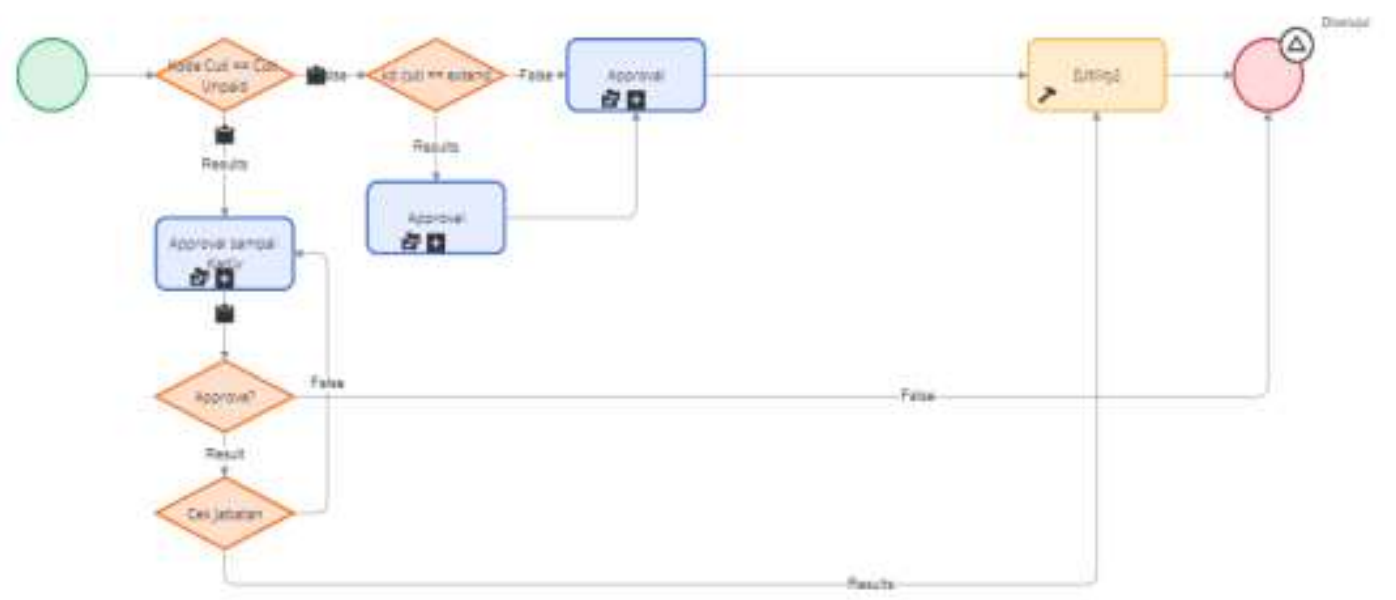

Gambar 6. Flow ApprovalAtasan

ApprovalRejection

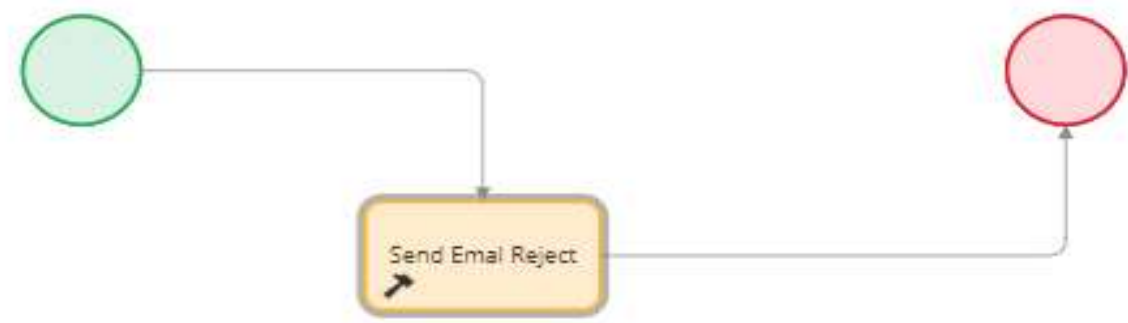

Gambar 7. Flow ApprovalReject 


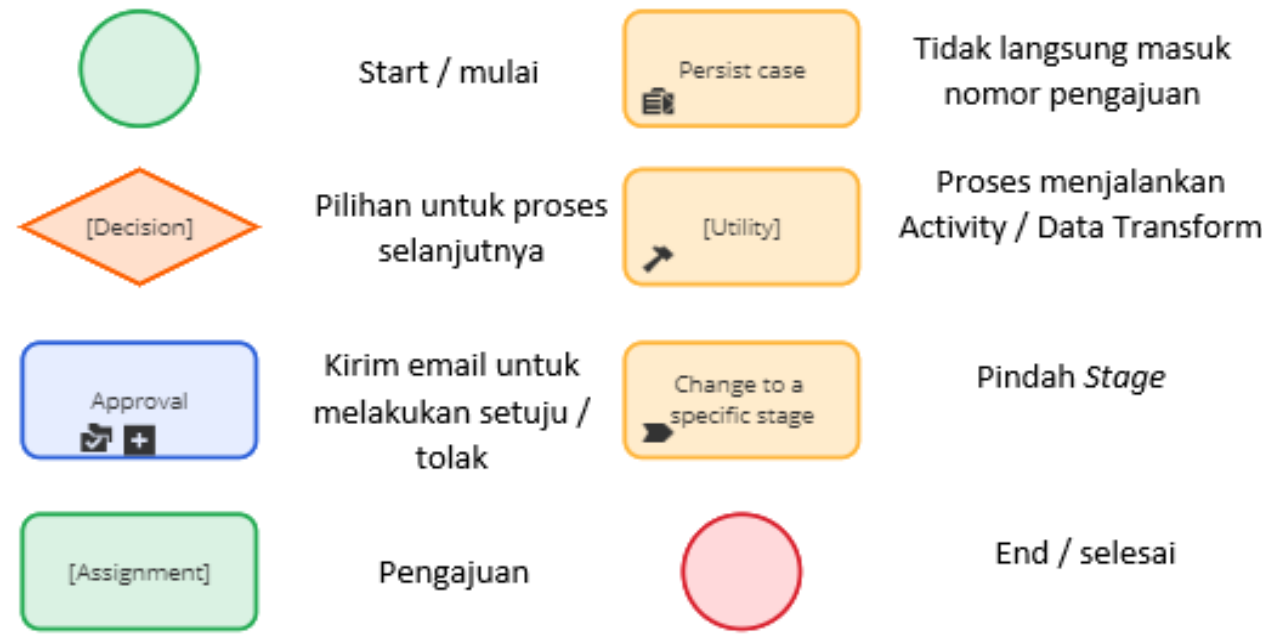

Gambar 8. Simbol Flow Diagram

Pada Flow Diagram tidak luput terdapat section, activity, dan Data Transform. Section berfungsi sebagai user interface atau tampilan untuk pengguna. Activity berfungsi untuk memproses kumpulan-kumpulan perintah yang sudah diatur kemudian dijalankan sesuai nomor step yang ada. Data Transform memiliki fungsi yang sama dengan Activity, hanya saja activity lebih banyak digunakan karena lebih mudah untuk digunakan.

Pada Gambar 9 adalah contoh section dari tampilan input pengajuan CIS yang digunakan sebagai form saat mengisi pengajuan.

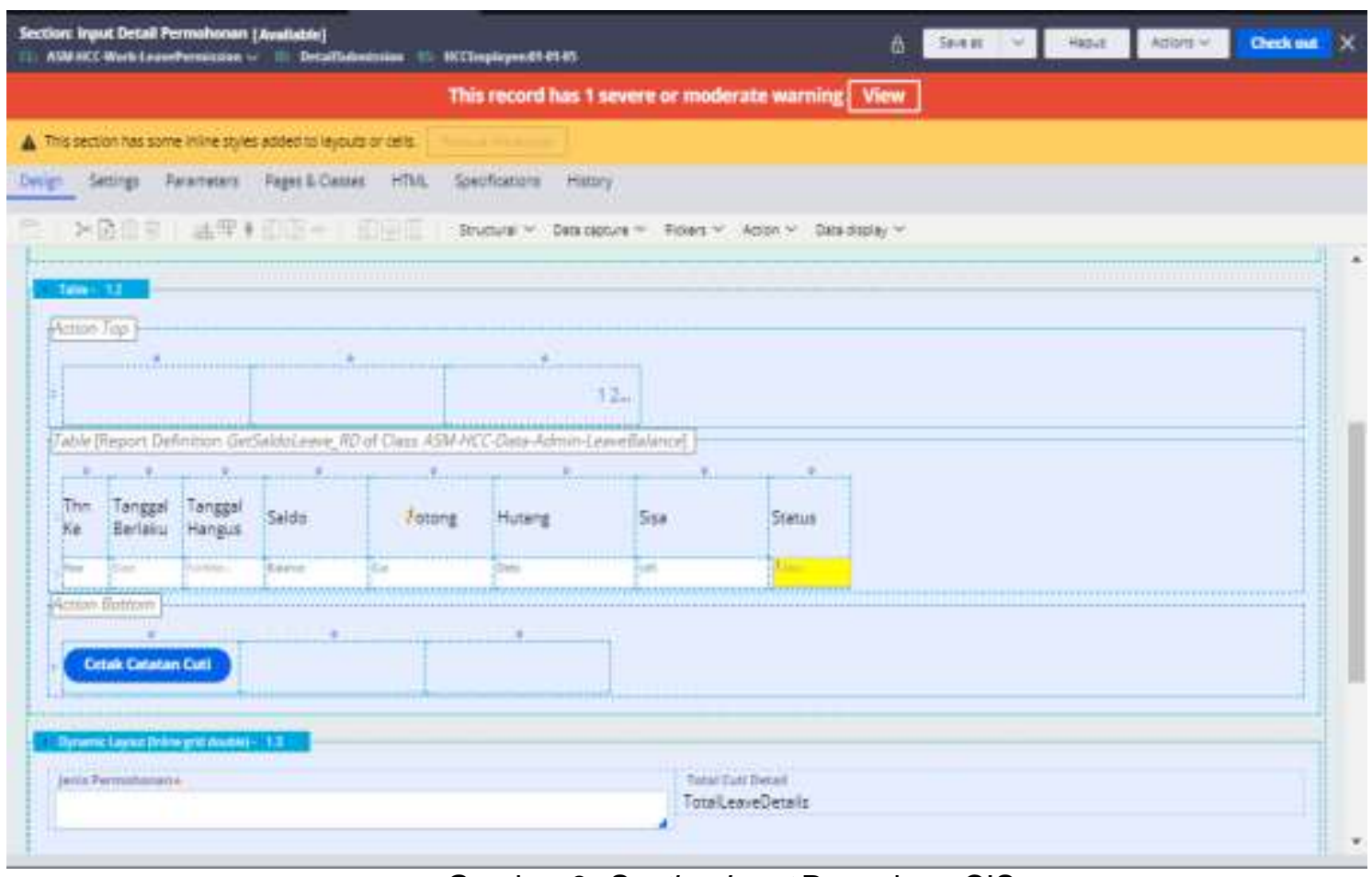

Gambar 9. Section Input Pengajuan CIS 
Pada Gambar 10 adalah contoh activity untuk melakukan proses update data karyawan. Activity ini berjalan ketika atasan telah melakukan approve pada pengajuan yang sudah diajukan oleh karyawan.

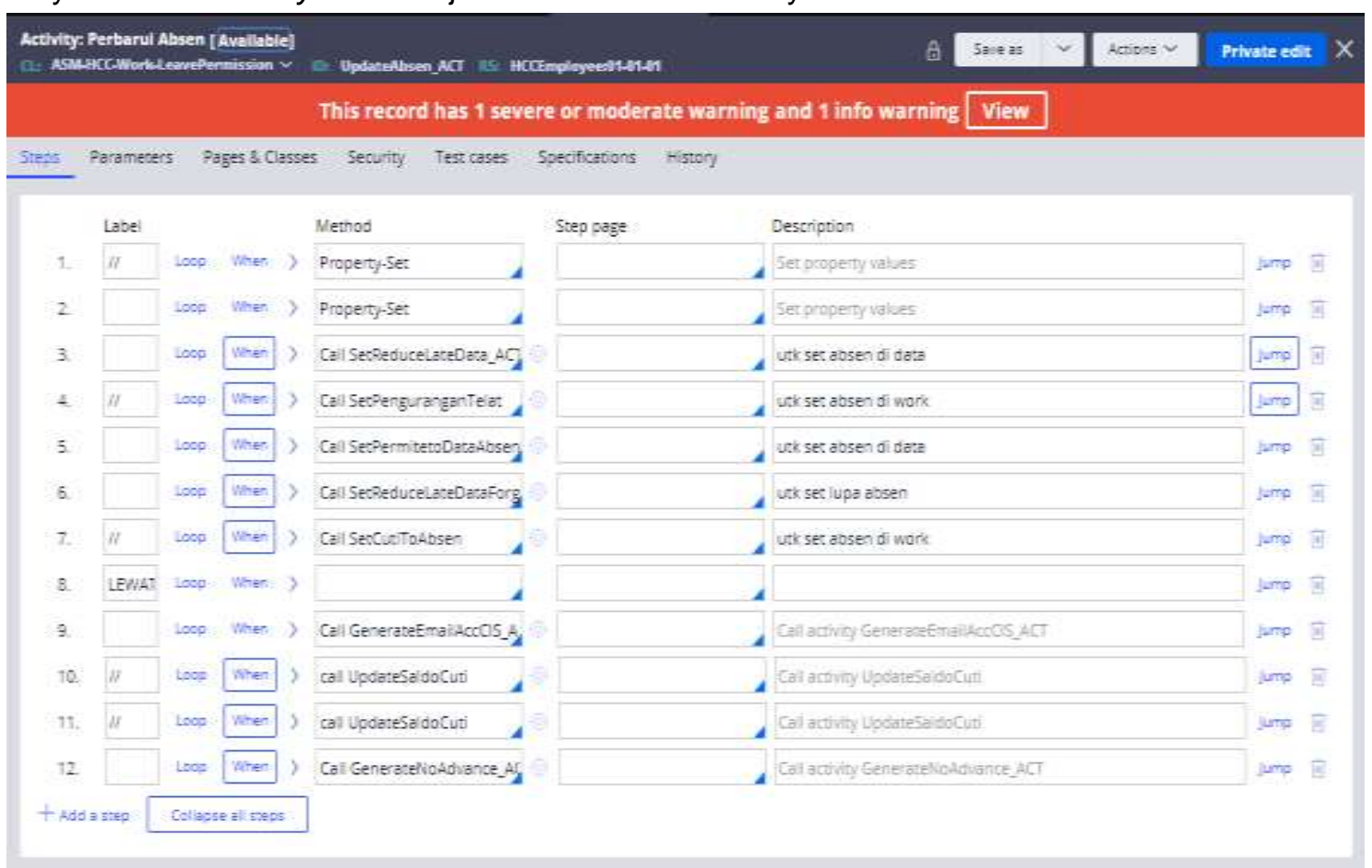

Gambar 10. Activiy Update Data Karyawan

Pada Gambar 11 adalah contoh Activity untuk pengiriman email. Activity ini berjalan ketika atasan telah melakukan approve atau reject pada pengajuan yang sudah diajukan oleh karyawan. Jika di- approve maka akan mengirimkan keterangan berisikan permintaan dengan status telah disetujui. Jika di-reject, keterangan akan berisikan status telah ditolak.

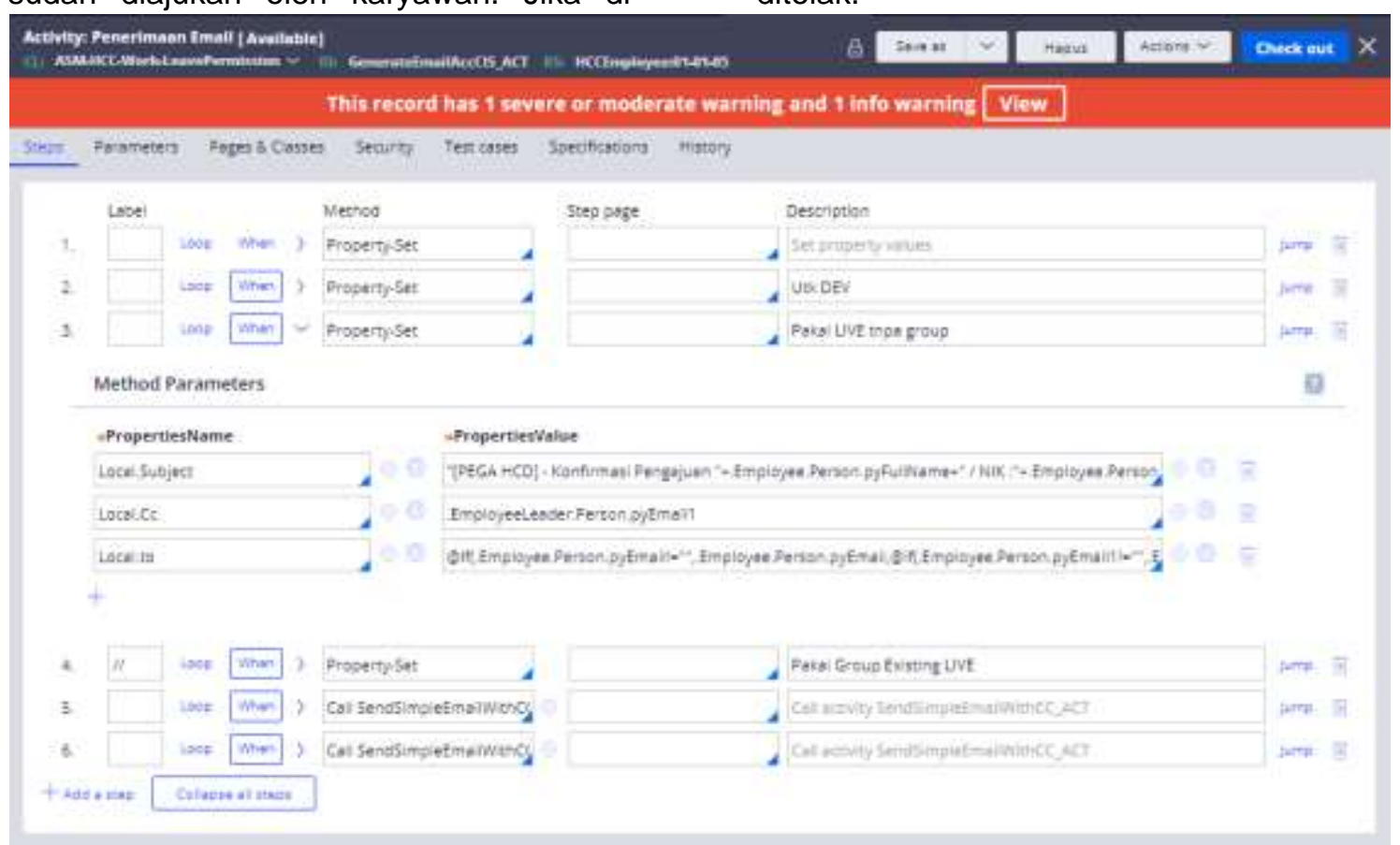

Gambar 11. Activity Send Email 
Implementasi

Pada bagian ini, akan dijelaskan proses jalannya sistem dari awal pengajuan dan akseptasi atasan sehingga terjadinya perubahan pada data karyawan.
Berikut merupakan tampilan awal dari pengajuan CIS. Dihalaman ini pengaju dapat melihat data diri dan absensi harian berdasarkan tanggal awal dan tanggal akhir kemudian klik tombol yang bertuliskan Cari.

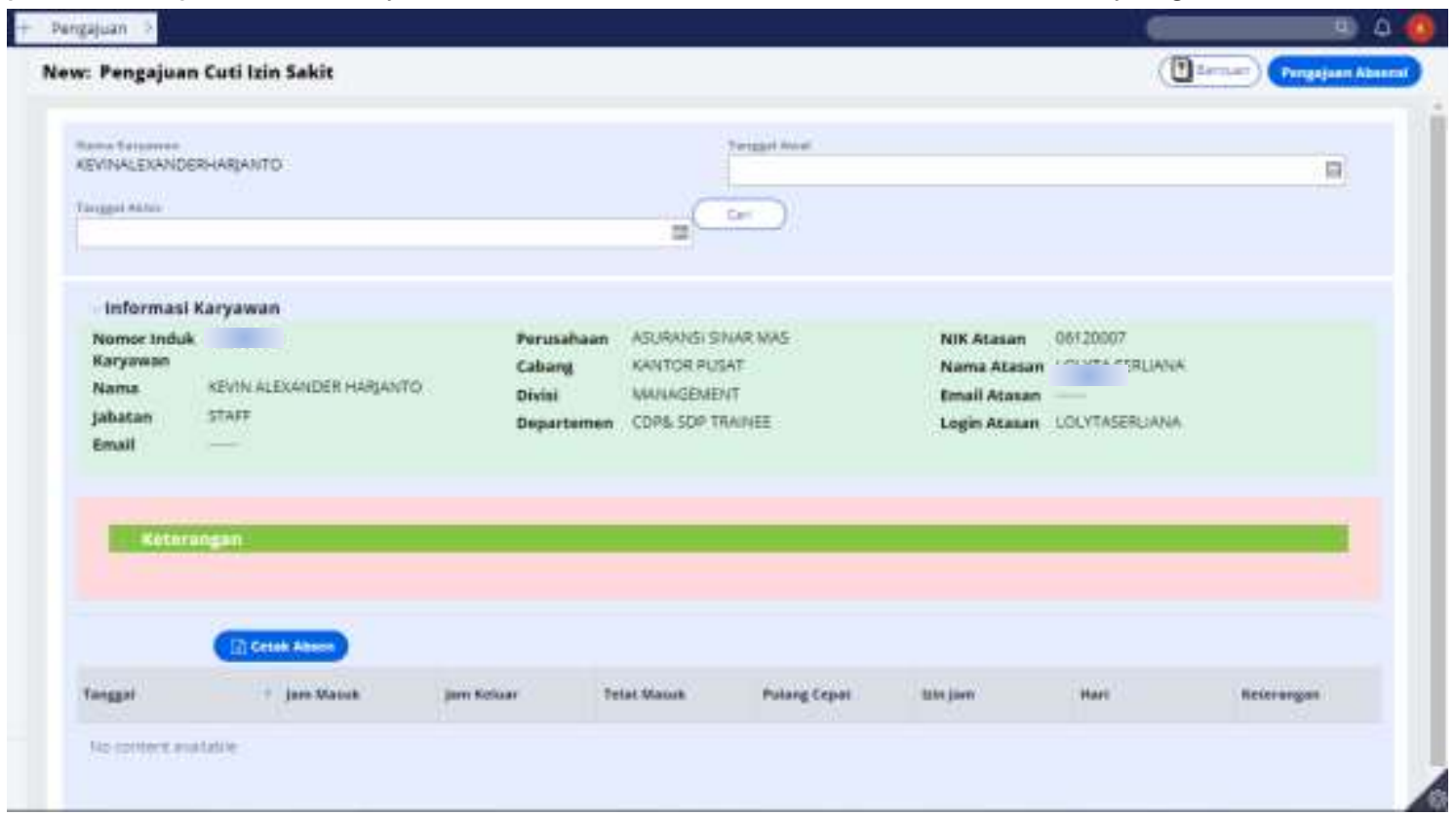

Gambar 12. Tampilan Awal CIS

Berikut merupakan tampilan pengajuan CIS setelah melakukan klik pada tombol Pengajuan Absensi yang terdapat kanan atas. Pada bagian ini karyawan diharuskan untuk memilih jenis pengajuan yang akan di ajukan dan memasukkan tanggal yang akan diajukan.

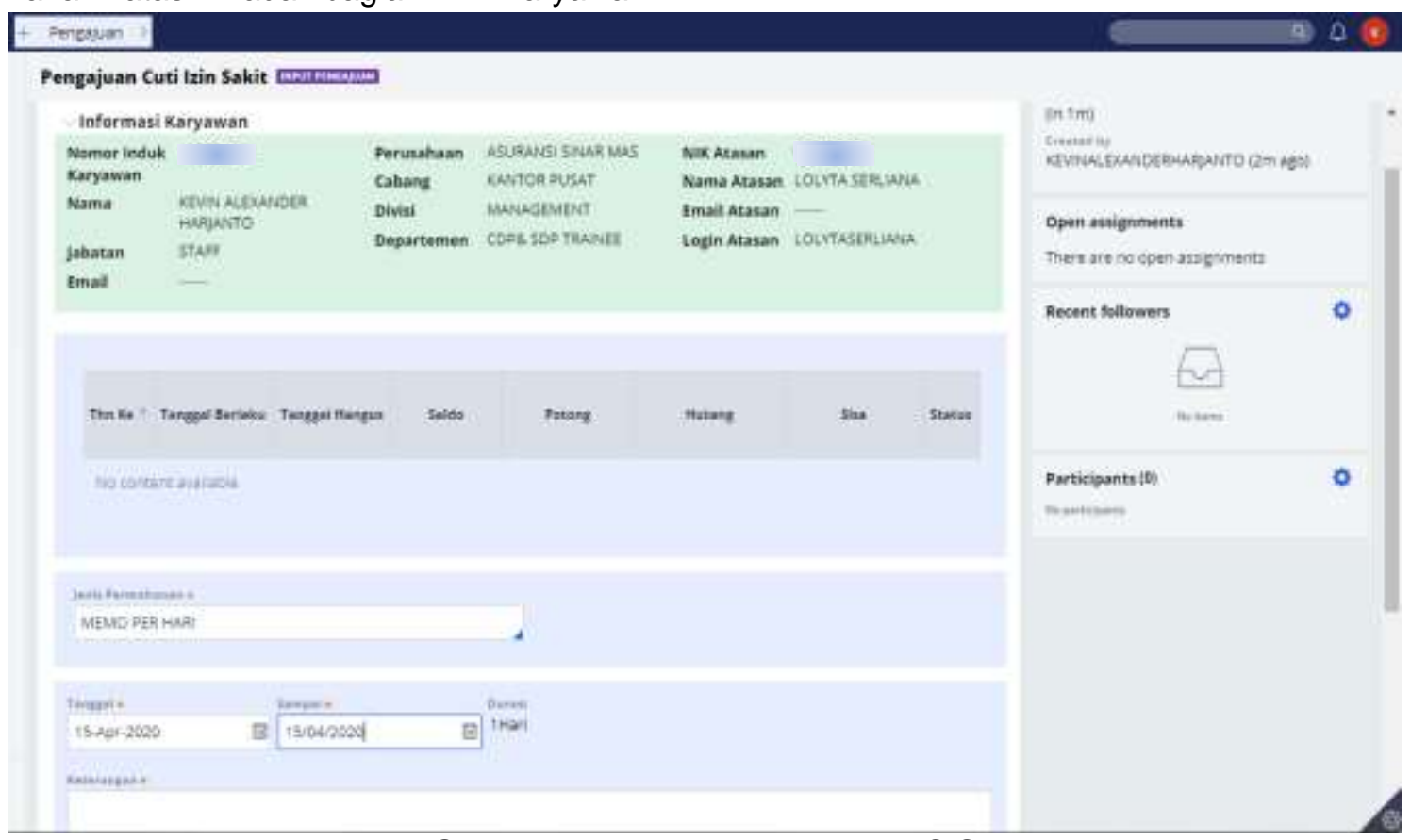

Gambar 13. Tampilan Pengajuan CIS 
Berikut merupakan tampilan pengajuan CIS saat atasan akan melakukan approve atau reject. Jika di approve maka data karyawan akan diperbarui sesuai dengan tipe pengajuan yang diajukan.

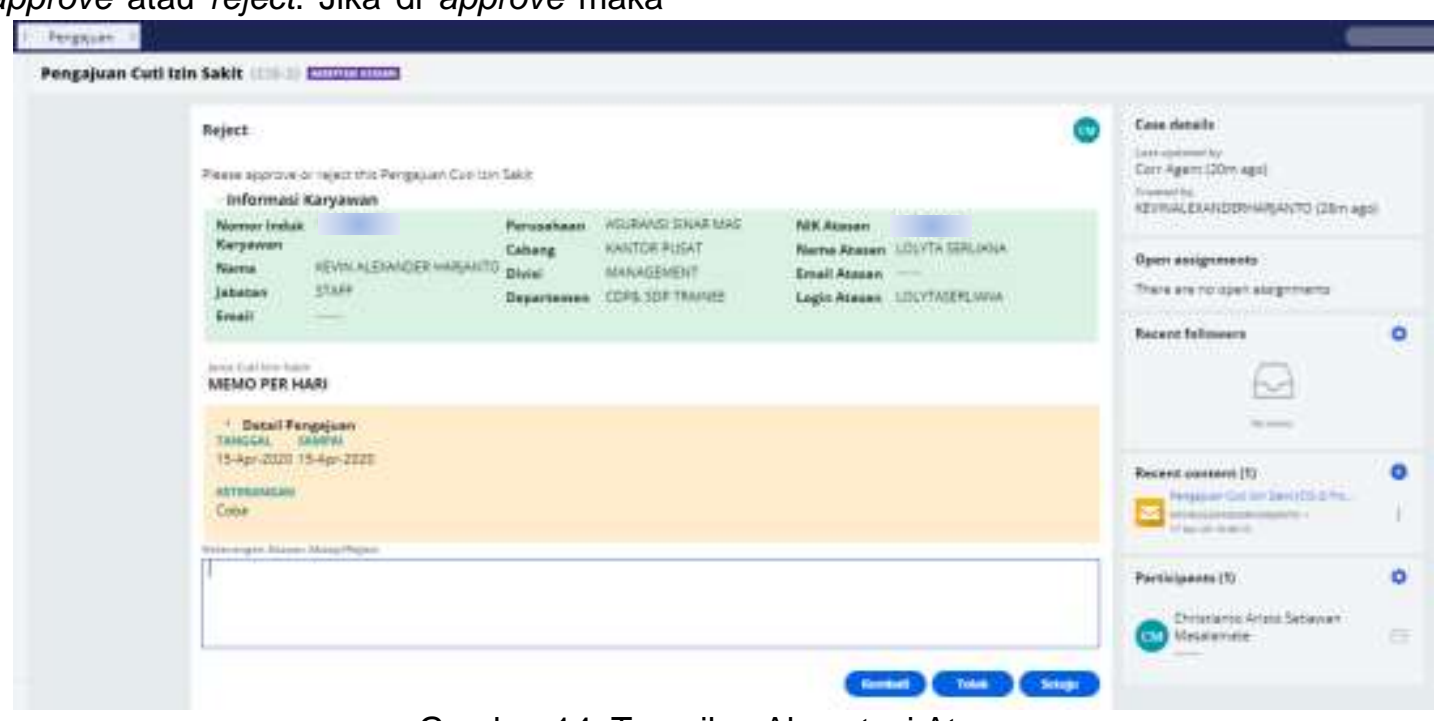

Gambar 14. Tampilan Akseptasi Atasan

Berdasarkan proses pengajuan di gambar 14 yang telah disetujui maka pengaju akan mendapatkan email yang berisikan keterangan seperti Gambar 15.

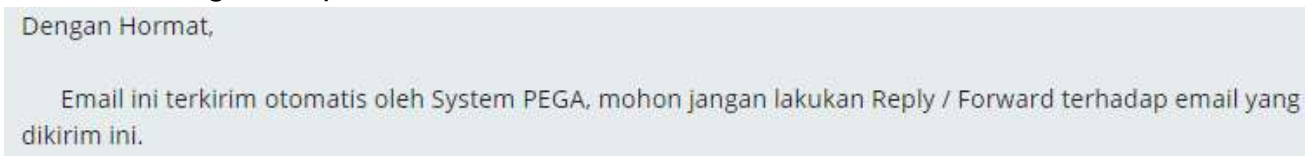

\section{Gambar 15. Tampilan Keterangan Email}

\section{Kesimpulan}

Berdasarkan hasil perancangan sistem pengajuan CIS di pega system 8, dapat disimpulkan bahwa Sistem ini dapat berjalan dengan baik dan sistem sudah sesuai kebutuhan yang diharapkan untuk karyawan. Sistem Pengajuan CIS dapat mempermudah kebutuhan karyawan karena dengan ada sistem ini dapat membuat waktu
Email tersebut berisikan data diri pengaju, jenis pengajuan, tanggal yang diajukan, dan alasan telah disetujui oleh atasan. 


\section{Referensi}

Chaudhari, Nikhil, Astitv Nagpal, and Santhi H. 2017. "BPM Development for Insurance Claims Using Pega." International Journal of $u$ - and $e$ Service, Science and Technology 10(7): 91-106.

http://article.nadiapub.com/lJUNESST vol10 no7/9.pdf

Darungo, Wilhelmus Joel et al. 2018. "Facultative Inward Application Design Using Pega Platform At Pt. Sinarmas Insurance." Universitas Kristen Satya Wacana 7(1): 37-43.

https://jurnal.uns.ac.id/itsmart/article/vi ew/20988

Kalluri, Kartheek. 2015. "Migrating Legacy System to Pega Rules Process." St. Cloud State University 7.

https://repository.stcloudstate.edu/cgi/ viewcontent.cgi?article $=1024 \&$ context =mme etds

Listiyoko, Langgeng, Achmad Fahrudin, and Ali Maksum. 2017. "Perancangan Aplikasi Cafe Untuk Efisiensi Order." : 113-20.

https://journal.untar.ac.id/index.php/JK I/article/view/7197https://journal.untar. ac.id/index.php/JKI/article/view/7197

Ratnawati, Dian Putri Dewi, and Made Subudi. 2018. "Pengaruh Talent Management Terhadap Employee Retention Dengan Employee Engagement Sebagai Variabel Mediasi
Fakultas Ekonomi Dan Bisnis Universitas Udayana, Bali, Indonesia Persaingan Usaha Pada Era Milenium Saat Ini Ditandai Dengan Perubahan Iklim Bisni." E-Jurnal Manajemen Unud 7(11): 6299-6325.

https://ojs.unud.ac.id/index.php/Manaj emen/article/view/40467

Revian Palpialy. $2018 . \quad$ "Perancangan Alternatif Penawaran Plan Small Medium Enterprise Menggunakan Pegasystems 7 ( Studi Kasus: PT . Asuransi Sinarmas )." 7(August): 22841.

https://journal.maranatha.edu/index.ph p/jutisi/article/view/1491

Satria Rachmadinata, Niko et al. 2014. "Pengaruh Manajemen Talenta... Pengaruh Manajemen Talenta Terhadap Kinerja Karyawan Lintasarta Kota Jakarta." : 197-204. http://journals.telkomuniversity.ac.id/ii m/article/view/1156

Setiyanto, Arif, Febriliyan Samopa, and Alwi. 2013. "Pembuatan Sistem Informasi Cuti Pada Kantor Pelayanan Perbendaharaan Negara Dengan Menggunakan PHP Dan MySQL." Teknik Pomits 2(2): 381-84. http://ejurnal.its.ac.id/index.php/teknik/ article/view/4817

PEGA 8 PT Asuransi Sinar Mas 2020. https://hcc.sinarmas.co.id/prweb

PEGA 7 PT Asuransi Sinar Mas 2020. http://pega7.sinarmas.co.id/prweb 